\title{
About the use of terrestrial experience for drilling wells water on the Mars surface
}

\author{
Lazar Avram ${ }^{1}$, Marius Stan ${ }^{2, *}$ \\ ${ }^{1}$ IME, the Petroleum Gas University of Ploiesti, upg-ploiesti.ro, Ploiesti, Romania \\ ${ }^{2}$ IPG, the Petroleum Gas University of Ploiesti, upg-ploiesti.ro, Ploiesti, Romania
}

\section{Email address:}

lavram@upg-ploiesti.ro(L. Avram),mstan@upg-ploiesti.ro(M. Stan)

\section{To cite this article:}

Lazar Avram, Marius Stan. About the Use of Terrestrial Experience for Drilling Wells Water on the Mars surface. Science Innovation. Vol. 1, No. 2, 2012, pp. 14-17. doi: 10.11648/j.si.20130102.11

\begin{abstract}
This paper will be based on the information already known about the Mars Planet, at international level and on the NASA and ESA preoccupations for finding a human team in order to establish new explorations of the planet resources in the near future, justifying in this way the opportunity of approaching this theme, and taking into account the preoccupations and the experience in the drilling domain of our country.
\end{abstract}

Keywords: Dynamic, Similitude, Gas Compressor, Drilling, Mars

\section{Introduction}

Based on the information communicated by Mars Global Surveyor, it has been affirmed that the lack of protection against the cosmic radiation made the martial atmosphere to be simply "blown" by the solar wind. Meanwhile, new facts have come to contradict that hypothesis.

The European explorer Mars Express, helped by the instrument ASPERA - 3 (Analyzer of Space Plasmas and Energetic Atoms) has also found that Mars is losing atmosphere, but it is all about 20 grams/ second.

Focusing upon this rhythm of loss of the atmosphere, then, in all its history, Mars has only lost a layer of water measuring few centimeters and only a thousandth of the Carbon Dioxide from the atmosphere.

As the NASA specialist claim, the explorer Mars Global Surveyor has already proved that liquid water sometimes flows on Mars. The natural question didn't impede to show up Does the undersoil of Mars hide large quantities of water and carbon dioxide? Here is a question that waits for an answer from the following missions.

Mars has an air-free atmosphere and lacks the magnetic field that might protect it against cosmic radiation. These cosmic radiations might kill any form of life present at the planet's surfaceThe four researchers continued afar. They realized a mathematic pattern of the martial shell, and then calculated the depth where the flux of cosmic radiation would be reduced enough to make life possible.

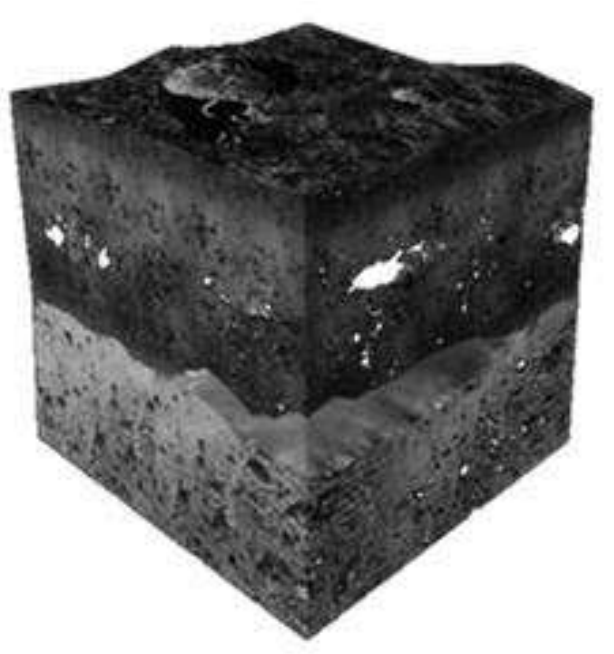

Figure 1. An aquifer model of Mars

So, the four researchers determined that life on Mars would only be possible at the depth of few meters. So, there should be dug really deep in order to detect it.

The four researchers continued afar. They realized a mathematic pattern of the martial shell, and then calculated the depth where the flux of cosmic radiation would be reduced enough to make life possible. So, the four researchers determined that life on Mars would only be possible at the depth of few meters. So, there should be dug really deep in order to detect it. 


\section{Similitude Theory Elements}

The theoretical base of modeling is made by the similitude theory. If a group of physical (engineering) phenomenon is described by the same general equations and has the same type of oneness conditions, presents a similitude between same class phenomenon, then there exists a bi-univocal correspondence between the points of their manifestation domains.

At the same time, the ratio between two scalar units of same nature from the corresponding points is constant.

We distinguish: the geometrical similitude, the cinematic similitude and the dynamic similitude.

The geometrical similitude is characterized by the constant ratio of all the homologous points ' coordinates of the object $\mathrm{M}(\mathrm{x}, \mathrm{y}, \mathrm{z})$ and the model $\mathrm{M}^{\prime}\left(\mathrm{x}^{\prime}, \mathrm{y}^{\prime}, \mathrm{z}^{\prime}\right)$ :

$$
\frac{x}{x}=\frac{y}{y}=\frac{z^{\prime}}{z}=\lambda_{l}=\text { const. }
$$

The cinematic similitude is characterized by the existence of the geometrical similitude and the constancy of the ratio of all the homologous times of object $t$ and model t':

$$
\frac{\grave{t}}{t}=\lambda_{t}=\text { const. }
$$

where $\lambda l$ is the length scale and $\lambda t$ is the time scale.

The velocity equations are:

$$
\begin{gathered}
v_{x}^{\prime}=\frac{d x^{\prime}}{d t^{\prime}}=\frac{d\left(\lambda_{l} x\right)}{d\left(\lambda_{l} t\right)}=\frac{\lambda_{l}}{\lambda_{t}} \cdot \frac{d x}{d t}=\lambda_{v} \cdot v_{x}, \\
v_{y}^{\prime}=\lambda_{v} \cdot v_{y} \\
v_{z}^{\prime}=\lambda_{v} \cdot v_{z}
\end{gathered}
$$

where $\lambda v$ is the velocity scale.

The acceleration equations are:

$$
\begin{gathered}
a_{x}^{\prime}=\frac{d^{2} x^{\prime}}{d t^{2}}=\frac{d}{d t^{\prime}}\left(\frac{d x^{\prime}}{d t^{\prime}}\right)=\frac{\lambda_{l}}{\lambda_{t}^{2}} \cdot a_{x}=\lambda_{a} \cdot a_{x} \\
a_{y}^{\prime}=\lambda_{a} \cdot a_{y} \\
a_{z}=\lambda_{a} \cdot a_{z}
\end{gathered}
$$

where $\lambda \mathrm{a}$ is the acceleration scale.

For the flows:

$$
Q^{\prime}=\frac{d V^{\prime}}{d t^{\prime}}=\frac{d\left(l^{3}\right)}{d t^{\prime}}=\frac{\lambda_{l}^{3}}{\lambda_{t}} \cdot \frac{d l^{3}}{d t}=\frac{\lambda_{l}^{3}}{\lambda_{t}} \cdot Q=\lambda_{Q} \cdot Q,
$$

where $\lambda Q$ is the flow scale.
The dynamic similitude is characterized by the existence of the cinematic similitude and the constancy of the homologous forces ratio:

$$
\frac{F_{x}^{\prime}}{F_{x}}=\frac{F_{y}^{\prime}}{F_{y}}=\frac{F_{z}^{\prime}}{F_{z}}=\lambda_{F}=\text { const }
$$

where the forces scale and the mass scale are:

$$
\lambda_{F}=\lambda_{m} \cdot \lambda_{l} \cdot \lambda_{t}^{-2}
$$

respectively

$$
\lambda_{m}=\frac{m}{m}
$$

There can be similarly defined, using the scales of the three fundamental units - length, mass, time - and the scales for the other derived units used in the technical systems modeling: the pressures invariant, the energy and mechanical work invariant and the power invariant.

The determining units are:

1 - length;

$\mathrm{v}$ - speed (velocity);

$\rho$-density;

$\mathrm{t}$ - time;

$\mathrm{p}$ - pressure;

$\mathrm{g}$ - gravitational acceleration;

$\mathrm{n}$ - rotation speed of gas compressor shaft;

$\mathrm{D}$ - diameter of the rotor-percussion drill that operates the drilling bit;

$\sigma-$ mechanical tensions;

$\rho$ - density of working agent; $\mathrm{Q}$ - flow;

\section{Similitude Criteria}

When analyzing the engineering systems through similitude between Earth and Mars, the following are adopted:the ratio of some unit's values derived in the two systems does not depend when choosing the fundamental units used for determining the derived units;if the measurement units variations of some fundamental physical units determine the variation of a derived physical unit, then a unique function exists (that can realize the correspondence between the respective fundamental units and the derived one).in the systems functioning, three fundamental physical units exist: the length $\mathrm{L}$, the mass $M$ and the time T;

For the two physical phenomenon, having the same class, to be similar, it is necessary and sufficient that their adequate similitude criteria to be equal, and the oneness conditions to be proportional.

For example, if the chosen measurements are unit $1(\mathrm{~m} 1)$, unit 2 (m2) and unit $3(\mathrm{~m} 3)$, by applying Theorem $\pi$, it results: 
$[\mathrm{L}] 0[\mathrm{M}] 0[\mathrm{~T}] 0=[\mathrm{m} 1] \alpha[\mathrm{m} 2] \beta[\mathrm{m} 3] \gamma \cdot\{[\mathrm{L}] \mathrm{a}[\mathrm{M}] \mathrm{b}[\mathrm{T}] \mathrm{c}\} \delta$

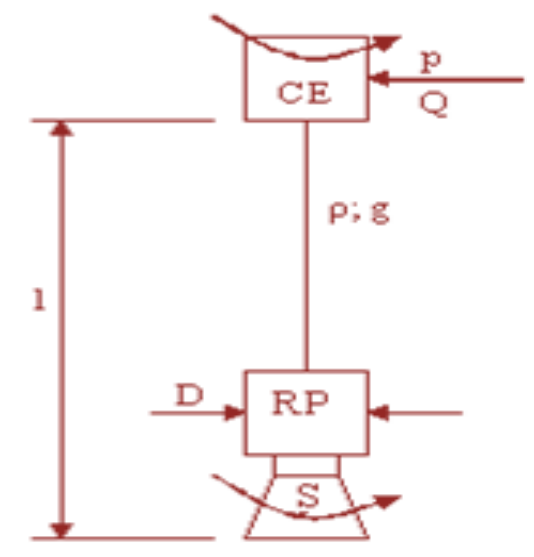

Figure 2. General scheme: $C E-$ helical compressor $\{p, Q, \rho\} ; R P-$ rotor-percussion $\{M, n, p, Q\} ; ; S-b i t\{M, n\}$

\section{Case Studies}

There can be used the correspondences from Table 1 in establishing the parameters of the homologous installation from Mars, knowing the planets' terrestrial values and gravitational accelerations.

So, the rotor-percussion action parameters $(\mathrm{p}, \mathrm{Q})$ will be found in the following correspondence relation:

$$
\left(\frac{n D l p}{\rho g Q}\right)_{P}=\left(\frac{n D l p}{\rho g Q}\right)_{M} .
$$

Considering the parameters values as being identical D- diameter; 1 - route length; $\rho$ - motor agent density -, it results:

$$
\left(\frac{n p}{g Q}\right)_{P}=\left(\frac{n p}{g Q}\right)_{M},
$$

Respectively:

$$
\left(\frac{n p}{Q}\right)_{M}=\frac{g_{M}}{g_{P}}\left(\frac{n p}{Q}\right)_{P}
$$

For the forces:

$$
\left(\frac{F t}{m \sqrt{l g}}\right)_{P}=\left(\frac{F t}{m \sqrt{l g}}\right)_{M} .
$$

Considering time, mass and length the same on Earth and Mars, it results:

$$
\left(\frac{F}{\sqrt{g}}\right)_{P}=\left(\frac{F}{\sqrt{g}}\right)_{M}
$$

Respectively:

$$
F_{M}=F_{P} \sqrt{\frac{g_{M}}{g_{P}}} .
$$

\section{Mars Drilling Equipment}

This phenomenon implies reporting the movement of some masses and fluids towards an inertial reference point where the masses forces are reduced to gravitational accelerations.

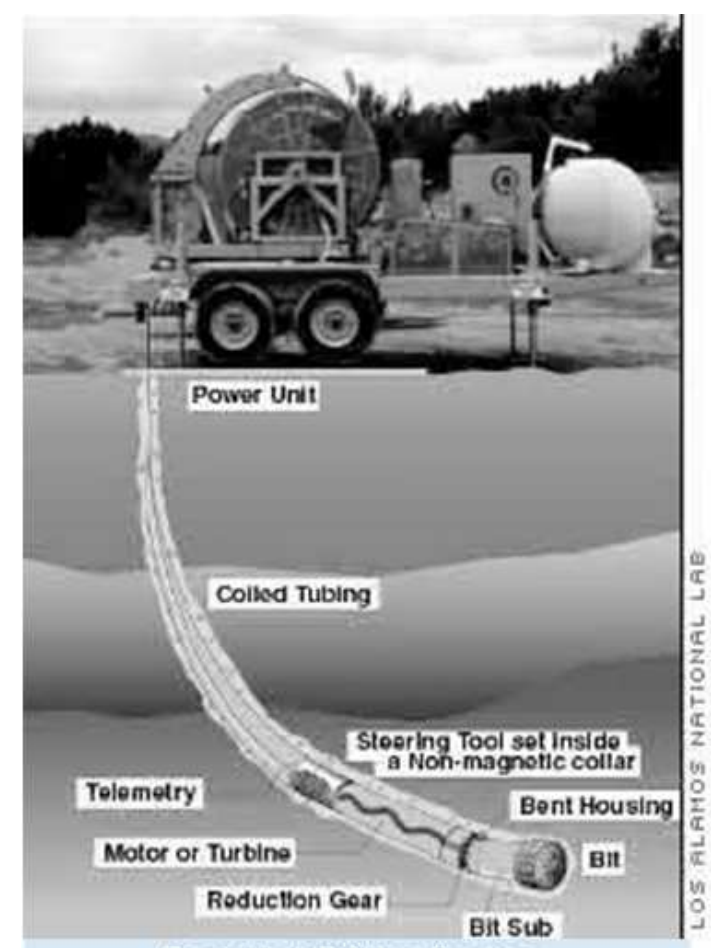

Rock Melt Drilling System

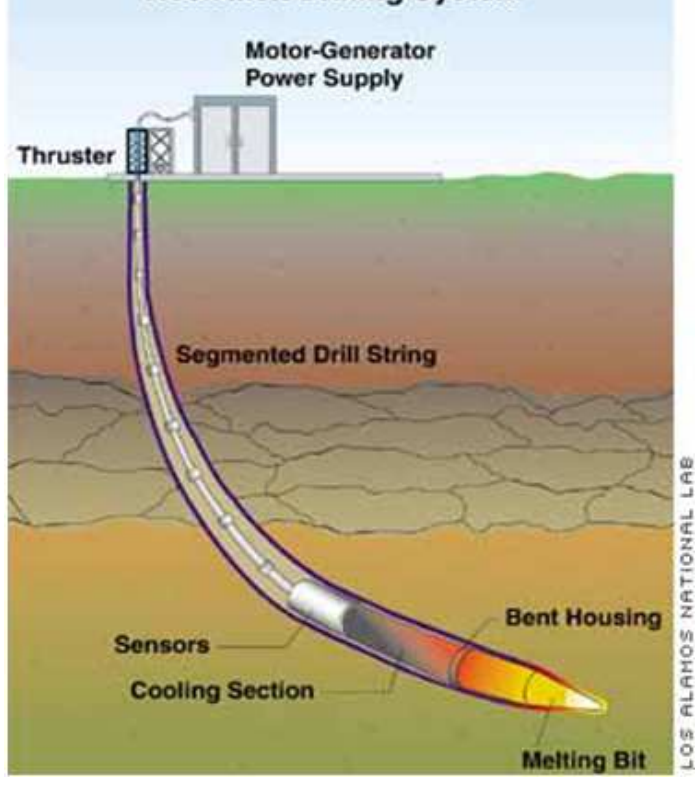

Figure 3. Coiled-tube drilling unit

This coiled-tube drilling unit, developed for earthbound drilling, could prove useful on Mars. Los Alamos designed 
a rock melter that could help avoid contamination of samples.

\section{Conclusions}

Drilling derricks on Mars will not take place with the aim of exploiting carbon deposits whose investment is debatable, but will have an exploratory character, that of discovering useful minerals and first of all, some water resources or/and thermal water resources.

The water derricks will be of paramount importance in the prospects of a future colonization of the planet and the project is included in the plan of interests of international spatial agencies, that conduct studies and researches on the atmosphere of the planet, from some of the accessed and notified data in various magazines resulting that the activity of exploring the martian soil will increase considerably in future time. (Tuesday,

It is known that the method, which is already a classic one, used mainly in drilling terrestrial derricks is that of hydraulic circular drilling.

Generally speaking, when undertaking drillings on Mars there occur problems caused by the environment(gravitation, atmosphere), the energy sources and the drilling fluid's composition. We turn the first problem, that of the energy source, to the specialists in the energy field to solve (for instance, the use of nonconventional sources of electrical energy that constitute the object of collateral interests and that we consider solved!)

Our approach to problems regarding gravitation will involve the theory of similitude. The circulation of the drilling fluid will be replaced by that of the gas that composes the planet's atmosphere: mainly carbon dioxide, similar to the case of drilling with air used in conditions that are specific to terrestrial drilling. The requirements of applying the method of circulation without liquid fluid will be analysed through similitude.

Furthermore, it is known that, presently, in order to "a drena" better the deposits of oil and terrestrial gas there are derricks to drill in all directions, including along the productive layers, derricks with many ramifications, derricks that use the effect of gravitational so on and so forth. But the most surprising development occurred at the level of conducted drilling in the exploitation of underwater resources and those located in hostile or inaccessible areas: under inhabited places, very steep fields or areas that are sensitive from an ecological point of view(lakes, gulfs, marshes, eternally frozen areas, so on and so forth). Why not continue to ask questions even regarding this planet, which is a Great Stranger in present time?

\section{Acknowledgements}

NASA thanks for articles and studies presented to INTERNET.

\section{References}

[1] Avram, L. Stan, M.: Making water wells on the surface of mars using terrestrial experience in the field and similarity theory, Journalof International Scientific Publications: Materials, Methods \& Technologies, Volume 4, 2010.

[2] Jeff Foust, Strategies for Martian exploration, The Space Review, January 24, 2005

[3] Golombek, Matthew P.: The Surface of Mars: Not Just Dust and Rocks. Science 300 (5628): 2043-2044. doi:10.1126/science.1082927. PMID 12829771 (2003-0627).

[4] Christensen, Philip R.; et al: Morphology and Composition of the Surface of Mars: Mars Odyssey THEMIS Results. Science 300 (5628): 2056-2061 (2003-06-27).

[5] Lazar Avram, Marius Stan, Quelques Aspects Concernant Le Forage Des Puits De L'eau Sur La Planète De Mars, Colloque international CITEF / IUT du Limousin,Limoges, France, 19 - 21 octobre 2011 « La gestion de l'eau, défi du XXIème siècle»

[6] Harvey, S.: Mars: Facts \& Figures. Solar System Exploration. NASA., May 27, 2008

[7] "NASA Images Suggest Water Still Flows in Brief Spurts on Mars". NASA/JPL. December 6, 2006. http://www.nasa.gov/mission_pages/mars/news/mgs20061206.html. Retrieved 2007-01-04

[8] Stan Marius, Avram Lazăr, About the Possibility of Exploration Drilling on the Planet Mars, The Smithsonian/NASA Astrophysics Data System, International Congress On Advances In Applied Physics And Materials Science. AIP Conference Proceedings, Volume 1400, pp. 303-306 (2011).

[9] "Water ice in crater at Martian north pole". ESA. July 28, 2005.

http://www.esa.int/SPECIALS/Mars_Express/SEMGKA808 BE_0.html. Retrieved 2010-03-19

[10] "Water May Still Flow on Mars, NASA Photo Suggests". NASA. December $6,2006$. http://www.npr.org/templates/story/story.php?storyId $=6587$ 226. Retrieved 2006-04-30.

[11] Williams, David R. (September 1, 2004). "Mars Fact Sheet". National Space Science Data Center. NASA. http://nssdc.gsfc.nasa.gov/planetary/factsheet/marsfact.html. Retrieved 2006-06-24.

[12] March 28, 2000 NASA Press Release summarizes the report of the Mars Program 